\title{
Common Hazards to Consider during Manufacturing of Feeds for Swine ${ }^{1}$
}

\author{
Taylor Langford, Morgan McKinney, Chad Carr, and Jason M. Scheffler ${ }^{2}$
}

\section{Introduction}

The Food Safety Modernization Act (FSMA) was signed into law in January of 2011. FSMA attempts to shift the focus of food safety from reacting to foodborne outbreaks to preventing them from occurring. The law stipulates that complying facilities that manufacture, process, pack, or hold food (hereafter referred to as feed) or feed ingredients for animals must implement a Hazard Analysis and Risk-Based Preventive Controls feed safety plan (FDA 2017c; Scheffler and Carr 2016). A Hazard Analysis and Risk-Based Preventive Controls feed safety plan has similarities to the Hazard Analysis and Critical Control Points (HACCP) commonly used in foods for humans such as meat, seafood, and juice, but it may be unfamiliar to facilities producing feed for livestock. More information on compliance requirements and the general structure of an animal food safety plan can be found at http://edis.ifas.ufl. edu/an330.

Many people are unaware that such measures are taken to prevent food safety hazards in animal feeds. The "Federal Food, Drug, and Cosmetic Act requires that all animal foods, like human foods, be safe to eat, produced under sanitary conditions, contain no harmful substances, and be truthfully labeled" (FDA 2016a). The animal and pet food industry is a multibillion-dollar industry that experiences recalls every year due to food safety hazards. It is estimated that the average cost of a recall to a food company is $\$ 10$ million. This includes losses directly associated with the affected food in addition to lost sales and brand damage (Grocery Manufacturers Association 2010). In some cases, the magnitude of the recall may be such a financial burden that companies do not recover from it. However, the implication of food safety hazards go beyond economics. Food safety hazards in animal feeds can also pose risks to humans. For example, animals consuming mycotoxincontaminated feeds can produce meat with toxic residues (Bennett and Klich 2003).

\section{What is a hazard analysis?}

The first step in writing a food safety plan is to conduct a hazard analysis. Hazards are defined as biological, chemical (including radiological), or physical agents that are known to be, or have the potential to be, associated with the facility or the animal food. A thorough hazard analysis should identify potential hazards and their frequencies and severities in order to determine methods of prevention. In many cases, hazards can be mitigated by following written Current Good Manufacturing Practices (CGMPs) and Standard Operating Procedures (SOPs). However, in some cases, hazards exist that require more robust controls called preventive controls. The determination of whether a hazard requires a preventive control depends on the frequency and severity, which can vary by facility and species being fed. This document discusses common biological, chemical, and physical hazards that may need preventive measures during

1. This document is AN357, one of a series of the Department of Animal Sciences, UF/IFAS Extension. Original publication date September 2019. Visit the EDIS website at https://edis.ifas.ufl.edu for the currently supported version of this publication.

2. Taylor Langford, graduate student; Morgan McKinney, graduate student; Chad Carr, associate professor; and Jason M. Scheffler, assistant professor, Department of Animal Sciences; UF/IFAS Extension, Gainesville, FL 32611.

The Institute of Food and Agricultural Sciences (IFAS) is an Equal Opportunity Institution authorized to provide research, educational information and other services

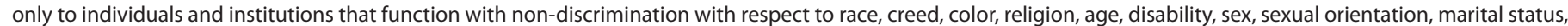

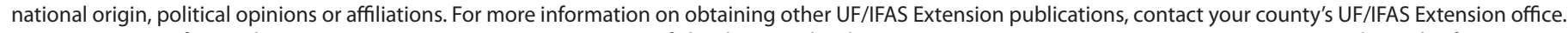
U.S. Department of Agriculture, UF/IFAS Extension Service, University of Florida, IFAS, Florida A \& M University Cooperative Extension Program, and Boards of County Commissioners Cooperating. Nick T. Place, dean for UF/IFAS Extension. 
the manufacture of swine feeds; however, this is not a comprehensive list. A thorough hazard analysis is required to identify hazards for each facility.

\section{What are common physical hazards to consider?}

Physical hazards can include stones, glass, metal, wood, plastic, or any physical object that could enter the feed and cause harm. The swine diet is typically mash or pelleted; it consists of grains which require harvest and processing with machinery and equipment. These processes can unintentionally introduce physical hazards, such as screws or shards of metal, to feed ingredients. A poorly located and unprotected light bulb has a risk of shattering. Tools, cell phones, glasses, and other objects may be misplaced or fall into processing equipment and become physical hazards in the feed.

The frequency and severity of a physical hazard are dependent upon each facility and process. Generally, pigs are considered "sorters," so the severity of many physical hazards would be considered low. However, a facility might choose to utilize a magnet or a screen to remove contaminants as part of its SOPs to reduce the frequency of the hazard. In addition, shatterproof bulbs can be strategically located to reduce the risk of glass contamination. Standard Operating Procedures for handling tools and personal items can mitigate the risk of those objects becoming physical hazards. Each facility should consider the source of feed ingredients, product flow, equipment, storage, packaging, and transport to determine points where physical hazards could enter the product and determine appropriate measures to prevent them.

\section{What are common biological hazards to consider?}

Ingredients, manufacturing equipment, or people can introduce biological hazards to feeds. Recent outbreaks have heightened concern for biosecurity because contaminated feeds are known to serve as vehicles for transmission of biological hazards (Cochrane et al. 2016; Dee et al. 2018).

Salmonella is considered the most prevalent biological hazard targeted for prevention in all animal feeds (Cochrane et al. 2016). Salmonella can persist for long periods of time in feed, and it often requires multiple approaches for control within feed mills (Jones 2011). Salmonella can cause disease in both humans and animals. However, the FDA only considers livestock feed (non-pet food) to be adulterated when it is contaminated with a Salmonella serotype that is considered pathogenic to the animal intended to consume the feed (FDA 2009). The most troubling serotype in swine feeds is Salmonella Choleraesuis, one of the most common organisms associated with swine pneumonia and septicemia (FDA 2009; Ritter and Striegel 2010). However, Cochrane et al. (2016) state that the probability of transmission of Salmonella Choleraesuis through feed is negligible, and it is not one of the top 25 Salmonella serotypes found in livestock feed ( $\mathrm{Li}$ et al. 2012). In addition, the risk that Salmonella in swine feeds and feed ingredients poses to humans is usually considered low due to limited human contact. However, each facility should assess the frequency and severity of an outbreak occurring by considering the Salmonella serotype, facility design, processes, and feed ingredients.

\section{Viruses}

Recently, outbreaks of porcine epidemic diarrhea virus (PEDV) and African swine fever (ASF) have brought about awareness within the animal food industry of the importance of biosecurity and risks of transmission through feeds. Viruses, especially PEDV, are particularly difficult to account for in a risk assessment because they can survive for long periods of time in key ingredients that are used to formulate swine feed rations, such as soybean meal, vitamin $\mathrm{D}$, lysine hydrochloride, and choline chloride (Dee et al. 2018). The risks associated with transmitting viruses through feeds and feed ingredients highlight the importance of sourcing ingredients from reputable suppliers and implementing biosecurity measures.

\section{What are common chemical hazards?}

The list of chemical hazards affecting swine feeds is longer and more complex than physical and biological hazards. Chemical hazards in animal feeds fall into three categories: naturally occurring, unintentionally introduced, and intentionally introduced. This section attempts to highlight the major chemical hazards associated with swine feeds, but it is not a comprehensive review of all chemical hazards that may occur. It is important to recognize that chemical hazards with the potential to affect animal feeds vary widely and are often difficult to predict. Use of a stringent prerequisite program and a thorough hazard analysis is important to predict and identify chemical hazards.

\section{Naturally Occurring}

Mycotoxins are the secondary metabolites produced by fungi, which are present in a variety of crops (Devreese, De 
Backer, and Croubels 2013). While fungi are considered biological systems, the mycotoxins produced by certain molds are classified as chemical hazards. There are several different kinds of mycotoxins, and their severity is dependent upon their concentration and the animal consuming the mycotoxin. Mycotoxin production is unavoidable and unpredictable due to the environmental factors that produce fungi. A thorough risk assessment is important for sourcing feed ingredients and managing storage conditions. Table 1 lists several mycotoxins to consider when producing and manufacturing swine feeds and their recommended maximum levels in feeds based on the intended animal consuming the feed product. More information about mycotoxins in swine feeds and problems associated with mycotoxin toxicity in swine can be found at https://vetmed. iastate.edu/sites/default/files/vdl/MycotoxinInfo.pdf.

Aflatoxins are the type of mycotoxins that are most concerning due to their frequency and severity. Aflatoxins can pose severe risks to human health and cause different levels of illness in animals. They are particularly worrisome because they can be transmitted from animal feed to milk, meat, and eggs. In addition, only very low levels of aflatoxins are necessary to exceed the FDA action level (20 ppb) in food for human consumption. Aflatoxins are poisonous by-products of the fungi Aspergillus flavus, Aspergillus parasiticus, and Aspergillus nomius, which are found in crops used as feedstuffs for livestock such as corn, peanut, and cottonseed. Caution is also advised for any feeds grown under tropical and subtropical conditions that are not dried or processed immediately after harvesting (FAO and IFIF 2010). Dry and hot climates result in corn prone to a much higher aflatoxin contamination risk (Medina, Rodriguez, and Magan 2014), so close attention should be paid to the source of corn and corn by-products. Monitoring the weather in the region where feedstuffs are being sourced can serve as a means to determine the likelihood of aflatoxin contamination and the needed measures to prevent contamination. Furthermore, insect and rodent infestation may facilitate mold proliferation in stored feedstuffs.

Other mycotoxins, such as ergots, fumonisin, trichothecene, zearalenone, deoxynivalenol, and T-2, are also common and are associated with disease in the pig (Iowa State University College of Veterinary Medicine 2018).

Antinutrients are common substances found in animal feeds and water. These substances (i.e., gossypol, glucosinolates, erucic acids, alkaloids) may reduce availability of nutrients and impair production, reproduction, and immunity of animals. Since swine are typically offered a sole-source feed, there is limited ability to compensate for insufficient or toxic levels of dietary nutrients. Caution is advised when using new alternative feed ingredients or industrial by-products, which may contain higher levels of antinutrients than expected.

In human food, undeclared allergens are a leading cause of recalls (FDA 2016b). However, allergens are not considered a serious hazard in animal feed. Allergies may generally manifest themselves as dermatitis in animals rather than as severe allergic reactions observed in humans. No serious adverse health consequences of allergens in animal food have been reported to the Reportable Food Registry from 2009 to 2014 (FDA 2016b).

\section{Unintentionally Introduced}

Unintentionally introduced chemical hazards in swine feeds are relatively infrequent, but their implications can be severe. Examples of unintentionally introduced chemical hazards include but are not limited to pesticides and other chemical residues, drug carryover, and nutrient deficiencies or toxicities.

Residues can occur because many crops used for animal feedstuffs are treated with pesticides and other chemicals to ensure acceptable or desired yields. In addition, the processes of harvesting and manufacturing expose feedstuffs to possible contamination by petroleum-based greases and other chemicals. These residues can pose risks to both animals and humans due to the accumulation of these products in fat tissues. The FDA Pesticide Monitoring Program suggests that very few animal feeds exceed permitted levels (FDA 2012). More information about pesticide residues in animal feedstuffs can be found in the Compliance Policy Guide Sec. 575.100 Pesticide Residues in Food and Feed (FDA 2017d). The likelihood of introduction of these chemicals to feedstuffs should be determined during a hazard analysis and appropriate prevention methods should be implemented.

Drug carryover is another important method of unintentionally introducing chemical hazards. Drug carryover is particularly important in facilities that manufacture or process feeds for multiple species. Certain animal species are fatally sensitive to drug residues which are important components of medicated feeds for other species. Ionophores are a class of antibiotics that change the population of microbes in the stomachs of intended animals in order to prevent coccidial infections and promote intestinal health. These substances are safe and useful in the correct dosage for the intended animal species, but they can cause serious problems if administered improperly or 
with other medications. Narasin is the only ionophore approved for use in swine diets and can be included in the diet at 15-30 ppm (Rovira and Sturos 2016). However, Narasin is toxic in excess and is also capable of interacting with other antibiotics such as tiamulin, a commonly used antibiotic for treatment of bacterial diarrhea in pigs (Carpenter, Charbonneau, and Josephson 2005). Monensin or monensin sodium, sometimes marketed under the trade name Rumensin ${ }^{\circledR}$ for cattle and Coban ${ }^{\circledR}$ for chickens, is a common ingredient used in many mixed-species feed mills. Monensin is toxic to pigs at rates of $10-20 \mathrm{mg} / \mathrm{kg}$, and it is lethal at $30 \mathrm{mg} / \mathrm{kg}$ (Dilov, Dimitrov, Dzhurov, Nikolov, and Panchev 1981). It is important to understand the possible risks that drug carryovers pose to different species as well as ways to effectively prevent these impacts. A facility that produces, packs, or holds feed for multiple species is at greater risk than others. The risks associated with drug residues are specific to each facility's ingredients and processes and should be controlled with appropriate prerequisite programs or preventive controls.

All medicated animal foods must be manufactured and distributed in accordance with the Current Good Manufacturing Requirements of Medicated Feeds (FDA 2017c). It is also important to note that feed additives containing medically important antimicrobials may fall under the Veterinary Feed Directive (VFD). The VFD brings therapeutic uses of drugs under veterinary supervision and requires a prescription to use medically important drugs in feed or water of food-producing animals. For more information about which feed additives may fall under the Veterinary Feed Directive, refer to the FDA's website on the Veterinary Feed Directive (FDA 2015b).

\section{NUTRIENT TOXICITIES AND DEFICIENCIES}

From a regulatory standpoint, nutrient toxicities and deficiencies are considered chemical hazards. Pigs are typically offered a sole-source diet, which limits the ability to select other feed sources to compensate for errors in formulation. Recalls related to nutrient deficiencies and toxicities are less common in swine feeds compared to feeds for other species such as cats, dogs, and sheep. Swine generally have a wide tolerance for most nutrients; reduced performance is a likelier outcome than illness or death. For many species, the diet is formulated based on crude protein. However, swine have well-defined requirements for specific amino acids that comprise proteins, allowing for more precise and lower-cost diet formulations. There are ten essential amino acids important to the swine diet: lysine, leucine, threonine, tryptophan, methionine, isoleucine, histidine, valine, arginine, and phenylalanine (Kansas State University 2007).
Cystine and tyrosine can be made from methionine and phenylalanine, respectively, but they can become limiting if levels of methionine and phenylalanine are insufficient. These amino acids, especially lysine, are important for muscle growth and efficiency provided there is adequate energy in the diet (Liao, Wang, and Regmi 2015). Vitamin $\mathrm{E}$, zinc, and iodine deficiencies in swine are less common today; however, they still occur due to feed mixing errors or an unbalanced diet. When manufacturing feeds for swine, especially complete feeds, it is important to make sure that all necessary nutrients are present and batches of feeds are continually monitored to prevent deficiencies.

Swine can also tolerate mineral levels beyond their requirements. However, any mineral can be toxic if consumed in excess. Selenium is an essential trace mineral that is routinely added in trace-mineral premixes in the diet. However, toxicity can occur at levels only slightly above requirements (Mavromichalis 2014). The FDA limits additions of selenium in the complete swine diet to $0.3 \mathrm{ppm}$ (FDA 2018a). Mineral toxicities are usually manifested by decreased animal performance, but extreme cases can result in chronic problems and death. In addition, many minerals have antagonistic properties and can interfere with normal absorption of other minerals. The mineral contents of by-product ingredients should also be monitored to prevent mineral toxicities, such as sulfur levels in distillers' grains.

Facilities producing feed for multiple species should be aware of the possible toxicities affecting each species. It is recommended to consult resources such as the National Research Council Nutrient Requirements of Swine (National Research Council 2012) to ensure toxicities and deficiencies are avoided.

\section{Intentionally Introduced}

Intentionally introduced chemical hazards can be any of the aforementioned hazards that are introduced to feedstuffs for economic gain or sabotage. The most well-known example is melamine in pet foods (FDA 2018b). Intentionally introduced hazards are difficult to predict and should be considered when reviewing CGMPs and SOPs to attempt to mitigate the risks.

\section{How do I prevent these hazards from occurring?}

There are multiple ways of preventing hazards from occurring in swine feeds. Appropriate methods of prevention usually depend on each hazard and its severity and likelihood of occurring. Robust CGMPs and SOPs are 
usually already in practice in most facilities, and many already work to prevent hazards that may occur. The hazard analysis may inform changes to existing CGMPs and SOPs specifically to reduce the probability that a hazard might occur. However, there are certain hazards that may require more intense methods of prevention due to their severity or frequency.

Some facilities choose to implement preventive controls and their required components to control hazards.

Preventive controls are additional actions taken to ensure the prevention of certain hazards (FDA 2017b). There are four forms of preventive controls: process controls, sanitation controls, supply-chain or supplier controls, and other controls (FDA 2017a). Process controls are the most common in a livestock feed facility and may include batching and sequencing procedures and daily reconciliation of specific ingredient use (e.g., monensin and other antibiotics).

The decision to use CGMPs and SOPs or preventive controls to control hazards depends on each facility and hazard. Some facilities may have to make business decisions regarding the type of ingredients to purchase or feeds to produce based on their ability to manage the risks associated with those products. It is important to note that decisions require justification for methods of prevention. Justification should be based on facility experience, illness data, scientific reports, and FDA resources. In addition, justification should be documented and provide a thorough explanation of the decision.

\section{Additional Resources}

FDA (key requirements for preventive controls for animal feed): http://www.fda.gov/downloads/Food/GuidanceRegulation/FSMA/UCM461884.pdf

FDA FSMA (animal feed overview): http://www.fda. gov/AnimalVeterinary/Products/AnimalFoodFeeds/ ucm347941.htm

UF/IFAS Department of Animal Sciences (FSMA): http:// animal.ifas.ufl.edu/FSMA/index.shtml

Food Safety Preventive Controls Alliance (FSPCA): https:// www.ifsh.iit.edu/fspca

Southern Center for FSMA Training: http://sc.ifas.ufl.edu/

\section{References}

Bennett, J. W., and M. Klich. 2003. "Mycotoxins." Clin. Microbiol. Rev. 16(3): 497-516. https://doi.org/10.1128/ CMR.16.3.497

Carpenter, J. A., G. Charbonneau, and G. Josephson. 2005. "Tiamulin and narasin toxicosis in nursery pigs." Journal of Swine Health Prod.: 333-336. https://www.aasv.org/shap/ issues/v13n6/v13n6p333.html

Cochrane, R. A., S. S. Dritz, J. C. Woodworth, C. R. Stark, A. R. Huss, J. P. Cano, R. W. Thompson, A. C. Fahrenholz, and C. K. Jones. 2016. "Feed mill biosecurity plans: A systematic approach to prevent biological pathogens in swine feed." Journal of Swine Health and Production 24(16): 154-164. https://www.aasv.org/shap/issues/v24n3/ v24n3p154.pdf

Dee, S., F. Bauermann, M. Niederwerder, A. Singrey, T. Clement, M. de Lima, C. Long, et al. 2018. "Survival of viral pathogens in animal feed ingredients under transboundary shipping models." PLOS One 1: 1-18. https://journals.plos. org/plosone/article?id=10.1371/journal.pone.0194509

Devreese, M., P. De Backer, and S. Croubels. 2013. "Overview of the most important mycotoxins for the pig and poultry husbandry." Vlaams Diergeneeskundig Tijdschrif: 171-180. http://vdt.ugent.be/sites/default/files/art82401.pdf

Dilov, P., S. Dimitrov, A. Dzhurov, A. Nikolov, and I. Panchev. 1981. "Toxicity of sodium monensin for pigs." Veterinarno-Meditsinski Nauki 18(8): 55-63.

FAO and IFIF. 2010. "Health hazards associated with animal feed." Good Practices for the Feed Industry-Implementing the Codex Alimentarius Code of Practice on Good Animal Feeding: 1-6. www.fao.org

FDA. 2001. "Guidance for Industry: Fumonisin Levels in Human Foods and Animal Feeds." Accessed on September 9, 2019. https://www.fda.gov/regulatory-information/ search-fda-guidance-documents/guidance-industryfumonisin-levels-human-foods-and-animal-feeds

FDA. 2009. "Guidance for FDA Staff: Compliance Policy Guide (December 2009)." Accessed on September 9, 2019. http://www.fda.gov/downloads/ICECI/ComplianceManuals/CompliancePolicyGuidanceManual/UCM192468.pdf 
FDA. 2010. "Advisory Levels for Deoxynivalenol (DON) in Finished Wheat Products for Human Consumption and Grains and Grain By-Products Used for Animal Feed." Accessed on September 9, 2019. https://www.oregon.gov/ ODA/shared/Documents/Publications/AnimalHealth/ DONGuidanceCVMV.pdf

FDA. 2012. "Pesticide Monitoring Program: Fiscal Year 2012 Pesticide Report." Accessed on September 9, 2019. http://www.fda.gov/downloads/Food/FoodborneIllnessContaminants/Pesticides/UCM432758.pdf

FDA. 2015a. "Compliance Policy Guide Sec. 683.100 Action Levels for Aflatoxins in Animal Feeds." Accessed on September 9, 2019. https://www.fda.gov/ICECI/ ComplianceManuals/CompliancePolicyGuidanceManual/ ucm074703.htm

FDA. 2015b. "Federal Register - Veterinary Feed Directive; Final Rule." Accessed on September 9, 2019. https://www. federalregister.gov/documents/2015/06/03/2015-13393/ veterinary-feed-directive

FDA. 2016a. "Pet Food.” Accessed on September 9, 2019. https://www.fda.gov/AnimalVeterinary/Products/AnimalFoodFeeds/PetFood/default.htm

FDA. 2016b. “The Reportable Food Registry: A five year overview of targeting inspection resources and identifying patterns of adulteration." U.S. Food and Drug Administration. Accessed on September 9, 2019. http://www.fda. gov/downloads/Food/ComplianceEnforcement/RFR/ UCM502117.pdf

FDA. 2017a. “21 CFR 507.34 Preventive Controls.” Accessed on September 9, 2019. https://www.accessdata.fda. gov/scripts/cdrh/cfdocs/cfCFR/CFRSearch.cfm?fr=507.34

FDA. 2017b. "21 CFR 507.42 Hazard Analyis and RiskBased Preventive Controls." Accessed on September 9, 2019. https://www.accessdata.fda.gov/scripts/cdrh/cfdocs/ cfCFR/CFRSearch.cfm?fr $=507.42$

FDA. 2017c. "Code of Federal Regulations Title 21, Part 225 Current Good Manufacturing Practice for Medicated Feeds." Accessed on September 9, 2019. https://www. accessdata.fda.gov/scripts/cdrh/cfdocs/cfcfr/CFRSearch. $\mathrm{cfm}$ ?CFRPart $=225 \&$ showFR $=1$
FDA. 2017d. "Compliance Policy Guides Sec. 575.100 Pesticide Residues in Food and Feed-Enforcement Criteria." Accessed on September 9, 2019. https://www.fda.gov/iceci/ compliancemanuals/compliancepolicyguidancemanual/ ucm123236.htm

FDA. 2018a. "21 CFR 573.920 Selenium.” Accessed on September 9, 2019. https://www.accessdata.fda.gov/scripts/ cdrh/cfdocs/cfcfr/CFRSearch.cfm?fr=573.920

FDA. 2018b. "Melamine Pet Food Recalls." Accessed on September 9, 2019. https://www.fda.gov/animal-veterinary/ safety-health/recalls-withdrawals

Grocery Manufacturers Association. 2010. Recall Execution Effectiveness: Collaborative Approaches to Improving Consumer Safety and Confidence. Accessed on September 9, 2019. https://www.gmaonline.org/downloads/research-andreports/WP_RecallExecution.pdf

Iowa State University College of Veterinary Medicine. 2018. "Mycotoxicoses." Accessed on September 9, 2019. https:// vetmed.iastate.edu/vdpam/FSVD/swine/index-diseases/ mycotoxicoses

Jones, F. T. 2011. "A review of practical Salmonella control measures in animal feed." Journal of Applied Poultry Research 20(1). https://doi.org/10.3382/japr.2010-00281

Kansas State University. 2007. "General Nutrition Principles for Swine." Accessed on September 10, 2019. https://www. bookstore.ksre.ksu.edu/pubs/MF2298.pdf

Li, X., L. A. Bethune, Y. Jia, R. A. Lovell, T. A. Proescholdt, S. A. Benz, T. C. Schell, G. Kaplan, and D. G. McChesney. 2012. "Surveillance of Salmonella prevalence in animal feeds and characterization of the Salmonella isolates by serotyping and antimicrobial susceptibility." Foodborne Pathogens and Disease 9(8): 692-698. https://doi. org/10.1089/fpd.2011.1083

Liao, S. F., T. Wang, and N. Regmi. 2015. "Lysine nutrition in swine and the related monogastric animals: Muscle protein biosynthesis and beyond." Accessed on September 10, 2019. https://doi.org/10.1186/s40064-015-0927-5

Mavromichalis, I. 2014. "Formulating pig diets: Selenium toxicity, deficiency." Accessed on September 10, 2019. https://www.wattagnet.com/articles/19843-formulatingpig-diets-selenium-toxicity-deficiency 
Medina, A., A. Rodriguez, and N. Magan. 2014. "Effect of climate change on Aspergillus flavus and aflatoxin B1 production." Frontiers in Microbiology 5: 1-7. https://doi. org/10.3389/fmicb.2014.00348

National Research Council. 2012. Nutrient Requirements of Swine. Washington, D.C.: The National Academies Press. https://www.nap.edu/read/13298/chapter/1

Osweiler. 1996. "Zearalenone levels in swine feeds." In Toxicology, The National Veterinary Medical Series for Independent Study. 398. Media, PA: Williams \& Wilkins.

Ritter, L., and D. Striegel. 2010. "Salmonella Choleraesuis in swine.” Accessed on September 10, 2019. https://articles.extension.org/pages/27268/salmonella-choleraesuis-in-swine

Rovira, A., and M. Sturos. 2016. "Diagnosis of ionophore intoxication in pigs." Accessed on September 10, 2019. https://www.nationalhogfarmer.com/nutrition/ diagnosis-ionophore-intoxications-pigs

Scheffler, J., and C. Carr. 2016. The Food Safety Modernization Act (FSMA) Preventive Controls for Animal Food. AN330. Gainesville: University of Florida Institute of Food and Agricultural Sciences. http://edis.ifas.ufl.edu/an330 
Table 1. Mycotoxin Levels in Swine Feeds ${ }^{a}$

\begin{tabular}{|c|c|c|c|c|c|}
\hline Fungus & Toxins & Intended Animal & Feed Ingredient(s) & $\begin{array}{l}\text { Recommended } \\
\text { Maximum Level }\end{array}$ & Reference \\
\hline \multirow[t]{4}{*}{ Aspergillus sp. } & \multirow[t]{4}{*}{$\begin{array}{l}\text { Aflatoxins } \\
\left(\mathrm{B}_{1}, \mathrm{~B}_{2}, \mathrm{G}_{1}, \mathrm{G}_{2}\right)\end{array}$} & Immature swine & $\begin{array}{l}\text { Corn, peanut products, } \\
\text { and other animal feeds } \\
\text { and ingredients, excluding } \\
\text { cottonseed meal }\end{array}$ & $20 \mathrm{ppb}$ & \multirow[t]{4}{*}{$\begin{array}{l}\text { FDA/ORG CPG 7126.33, Sec } \\
683.100 \\
\text { (FDA 2015a) }\end{array}$} \\
\hline & & Breeding swine & Corn and peanut products & $100 \mathrm{ppb}$ & \\
\hline & & $\begin{array}{l}\text { Finishing swine } \geq \\
100 \mathrm{lb}\end{array}$ & Corn and peanut products & $200 \mathrm{ppb}$ & \\
\hline & & All swine & Cottonseed meal & $300 \mathrm{ppb}$ & \\
\hline Fusarium sp. & $\begin{array}{l}\text { Fumonisins } \\
\left(\mathrm{B}_{1}, \mathrm{~B}_{2}, \mathrm{~B}_{3}\right)\end{array}$ & All swine & White and yellow corn & 20 ppm & $\begin{array}{l}\text { US FDA Final Guidance, Nov. } \\
9,2001 \\
\text { (FDA 2001) }\end{array}$ \\
\hline Fusarium sp. & $\begin{array}{l}\text { Vomitoxin } \\
\text { (Deoxynivalenol, } \\
\text { DON) }\end{array}$ & All swine & $\begin{array}{l}\text { Corn, milo, wheat, rye, barley, } \\
\text { and other cereal crops }\end{array}$ & $5 \mathrm{ppm}$ & $\begin{array}{l}\text { FDA Advisory } \\
\text { (FDA 2010) }\end{array}$ \\
\hline \multirow[t]{4}{*}{ Fusarium sp. } & \multirow[t]{4}{*}{ Zearalenone } & Prepubertal gilts & \multirow[t]{4}{*}{ Corn, wheat, barley, milo, oats } & $<1 \mathrm{ppm}$ & \multirow{4}{*}{$\begin{array}{l}\text { Toxicology, The National } \\
\text { Veterinary Medical Series for } \\
\text { Independent Study } \\
\text { (Osweiler 1996) }\end{array}$} \\
\hline & & $\begin{array}{l}\text { Sexually mature and } \\
\text { bred sows }\end{array}$ & & $<3 \mathrm{ppm}$ & \\
\hline & & Young boars & & $<20 \mathrm{ppm}$ & \\
\hline & & Mature boars & & $<200$ ppm & \\
\hline
\end{tabular}

